\title{
Redes interorganizacionais e criação de valor corporativo no Brasil
}

\author{
Danival Sousa Cavalcante \\ https://orcid.org/0000-0002-7474-1480 | E-mail:danivalsc@hotmail.com
}

Alessandra Carvalho de Vasconcelos

https://orcid.org/0000-0002-6480-5620 | E-mail: alevasconcelos.ufc@gmail.com

Vanessa Ingrid da Costa Cardoso

https://orcid.org/0000-0003-4174-9686 | E-mail: nessaingrid@gmail.com

Marcus Vinícius Veras Machado

http://orcid.org/0000-0001-6787-4333 | E-mail: marcusmachado@ufc.br

\section{Resumo}

Objetivo: Esta pesquisa investiga a relação entre a prática de redes interorganizacionais e a criação de valor corporativo em 218 companhias não financeiras listadas na B3.

Método: Com o apoio de técnicas de estatística descritiva, inferencial e multivariada, foram analisadas informações do ano de 2016 relacionadas aos 2.080 conselheiros e diretores, totalizando 15.611 dados, extraídos dos formulários de referência e da Economática ${ }^{\circledR}$.

Resultados: Verificou-se que as empresas têm maior probabilidade de criar valor se limitarem o compartilhamento de seus conselheiros e diretores com outras empresas em até 8 interlockings e possuírem no mínimo 2 e no máximo 4 conselheiros independentes em suas estruturas administrativas.

Contribuições: Conclui-se, com fundamento na teoria da Dependência de Recursos, que empresas conectadas em rede, por meio de board interlocking, podem contribuir para melhorar a atividade econômica umas das outras, além de sugerir que a existência de laços corporativos favorece a criação de valor corporativo.

Palavras-chave: Redes interorganizacionais. Board interlocking. Teoria da Dependência de Recursos. Alta administração. Criação de valor. 


\section{Introdução}

A partir da formação de redes interorganizacionais, constituídas por meio de canais de relacionamento entre organizações, também conhecidos por outras nomenclaturas, como alianças estratégicas, parcerias corporativas, network organizacional, redes sociais corporativas, as estratégias corporativas podem se materializar com o apoio interorganizacional. Neste estudo, adota-se para tais relacionamentos o termo "redes interorganizacionais".

As parcerias entre organizações podem advir de interesses corporativos ligados à redução dos custos dos processos, aquisição de informação e de aprendizado (Larentis, Antonello, Milan \& De Toni, 2014), as quais representam possíveis fontes de vantagens competitivas. Para Ribeiro e Colauto (2016), as empresas estão mais inclinadas a adotar práticas organizacionais comuns quando compartilham seus conselheiros e diretores com outras empresas alinhadas estrategicamente com a tendência de relacionamento coletivo e processo decisório uniforme.

Nesse contexto, uma das formas de a empresa constituir e fortalecer parcerias estratégicas consiste no entrelaçamento e formação de redes de relacionamento dos membros da alta administração com os de outras empresas, incluindo nesse grupo os membros do conselho de administração e os diretores, de modo a ampliar o network, prática denominada board interlocking, que é tida como uma fonte de facilitação de acesso a recursos externos (Hillman, Cannella \& Paetzold, 2000). O board interlocking representa relações sociais entre duas ou mais empresas por meio do compartilhamento de um mesmo profissional da administração (Fich \& White, 2005; Ribeiro \& Colauto, 2016).

A formação de redes interorganizacionais pode ser explicada a partir de diferentes teorias, como, por exemplo, da Agência, dos Custos de Transação, dos Custos de Agência ou da Dependência de Recursos. A escolha da teoria para explicar as redes interorganizacionais depende das finalidades para as quais as redes são constituídas. Para este estudo, a formação de redes fundamenta-se na teoria da Dependência de Recursos, que ajuda a explicar as razões das conexões de redes entre companhias (Hillman et al., 2000), quando os membros da alta administração atuam como conexões entre as firmas, facilitando o acesso a recursos externos em prol de objetivos comuns (Zald, 1969).

Ribeiro e Colauto (2016) explicitam que a teoria da Dependência de Recursos ajuda a explicar o conselho de administração como um mecanismo facilitador do acesso da organização a recursos externos, que são essenciais para o desenvolvimento da firma em médio e em longo prazo. Além disso, as relações empresariais permitem as empresas o acesso a parceiros comerciais, propiciando apreensão de conhecimentos específicos e estratégicos.

No tocante aos efeitos das redes interorganizacionais no valor corporativo, Almeida e Machado (2013) apontam que as empresas que atuam em apenas um mercado enfrentam dificuldades para se expandir, mas, por meio de alianças, encontram uma forma competitiva de criar valor. $\mathrm{O}$ efeito contrário foi notado por Santos e Silveira (2007), indicando que altos níveis de interlocking prejudicam o valor da firma. Já Aranha, Rossoni e Mendes-da-Silva (2016) constataram associação positiva entre o board interlocking e o desempenho empresarial.

Diante do exposto e considerando resultados conflitantes e inconclusivos apresentados na literatura, emerge o interesse em responder à seguinte questão-problema: Qual a relação entre a prática de formação de redes interorganizacionais e a criação de valor nas companhias de capital aberto no Brasil? Destarte, constitui objetivo principal deste estudo investigar a relação entre a prática de formação de redes interorganizacionais, por meio do board interlocking, e a criação de valor nas companhias de capital aberto no Brasil. Adicionalmente, busca-se descrever as características das redes no ambiente corporativo brasileiro, além de comparar as empresas participantes de redes com as demais no tocante à criação de valor. 
Assim, considerando-se que as empresas realizam alianças com outras empresas para encontrar uma forma competitiva de criar valor (Almeida \& Machado, 2013), que há indícios de valores ótimos (que maximizam o valor e o desempenho empresarial) da centralidade da empresa, no âmbito da rede de relações corporativas (Mendes-da-Silva, 2011), e que a prática controlada, sem excessos, de interlocking pode contribuir para a criação de valor (Santos \& Silveira, 2007), este estudo, fundamentado na teoria da Dependência de Recursos, define como hipótese que a formação de redes, por meio da prática de board interlocking, contribui para a criação de valor nas companhias abertas.

Nesse sentido, espera-se que as empresas participantes de redes sociais corporativas maximizem sua potencialidade para acessar recursos e conhecimentos estratégicos externos, resultando na maximização de seu valor, superior ao das empresas que não se relacionam em redes interorganizacionais por meio da prática de board interlocking.

Destaca-se que a cada dia os temas redes interorganizacionais e a criação de valor corporativo despertam atenção e interesse dos stakeholders. Assim, busca-se contribuir para a evolução sistemática dos estudos que abordam as temáticas, considerando que os estudos apresentam medidas de desempenho em vez de criação de valor, além de resultados inconclusivos (Camargos \& Barbosa, 2009; Lamb, 2017; Larentis et al., 2014; Marchi, Cassanego \& Wittmann, 2012; Kaczmarek, Kimino \& Pye, 2014; Santos \& Silveira, 2007; Vedel, 2016). Busca-se ainda contribuir para a ampliação da literatura que trata sobre redes sociais corporativas, utilizando uma abordagem de relacionamento dos seus elementos constitutivos, originada do board interlocking, haja vista a ainda pouca exploração nacional dos temas conjuntamente (Balestrin, Verschoore \& Reyes, 2010).

\section{Revisão de Literatura}

\subsection{Teoria da dependência de recursos e as redes interorganizacionais}

Na teoria da Dependência de Recursos, o conselho de administração e os diretores, atuando como canais de conexão entre empresas no ambiente corporativo, agem como mecanismos de gestão de recursos externos, redutor de incertezas e, ainda, de diminuição dos custos de transação (Pfeffer \& Salancik, 1978). Para Hillman et al. (2000), a teoria da Dependência de Recursos ajuda a entender o conselho de administração como um mecanismo facilitador do acesso da empresa aos recursos externos.

O acesso aos recursos externos é facilitado quando as corporações estabelecem ligações entre si por meio dos membros da sua alta administração, porque estes tendem a trabalhar em prol de objetivos comuns (Zald, 1969). Nesse contexto, as firmas devem ser compreendidas por meio de sua interdependência com o ambiente (Pfeffer \& Salancik, 1978).

O compartilhamento de membros da alta administração entre empresas é um dos mecanismos utilizados para facilitar o acesso a tais recursos, prática conhecida como board interlocking. Conforme Cunha e Piccoli (2017), tal fenômeno contribui para a disseminação de práticas gerenciais e de governança, a partir do compartilhamento de conhecimentos e experiências dos conselheiros em outros conselhos, inclusive de estratégias empresariais.

No cenário corporativo cada vez mais competitivo, o desafio para as empresas é alinhar a estratégia dos negócios com os interesses dos acionistas, em um ambiente em que os acionistas visam obter maior valor corporativo. Nesse sentido, a prática de board interlocking pode refletir no desempenho da empresa (Aranha et al., 2016).

Depreende-se, portanto, que a formação de redes interorganizacionais, por meio da prática de board interlocking, fundamentada na teoria da Dependência de Recursos, ajuda a explicar as razões das conexões das companhias em rede. Gobibi, Cunha, Brito e Senger (2005) argumentam que mecanismos como a percepção da dependência entre as partes, o desenvolvimento da cooperação e o estabelecimento da confiança ajudam a assegurar a ação conjunta entre as empresas. 
Para Ribeiro, Colauto e Clemente (2016), a teoria da Dependência de Recursos busca explicar a ocorrência do board interlocking no ambiente organizacional como uma interligação de empresas como fonte de captação de recursos essenciais para o seu progresso, proveniente de fontes externas. Assim, a teoria da Dependência de Recursos contribui para enriquecer os estudos que ajudam a compreender o conselho de administração como um mecanismo facilitador do acesso da organização a recursos externos (Ribeiro \& Colauto, 2016).

Balestrin et al. (2010) explicam que tais relacionamentos resultam de organizações que adotam algum tipo de estratégia cooperativa ou interorganizacional para alcance de objetivos individuais e coletivos, enquanto permanecem autônomas e independentes.

Contudo, nem sempre os interesses são harmônicos e convergentes. Segundo Gobibi et al. (2005), a rede constitui um espaço plural onde diferentes agentes coexistem com diferentes capitais e interesses, o que pode gerar situações de conflitos e disputas, em detrimento do consenso e da harmonia que predominam nas investigações nesse campo organizacional.

Para os propósitos deste estudo, as redes interorganizacionais são analisadas a partir do compartilhamento de conselheiros e diretores entre duas ou mais empresas, concomitantemente, o que equivale ao board interlocking, que são ligações por meio da participação do mesmo profissional na administração de ambas (Fich \& White, 2005; Ribeiro \& Colauto, 2016). Para Pfeffer \& Salancik (1978), quando uma organização nomeia um profissional para integrar seu conselho de administração, esperase que este propicie recursos que a ajudem a se estruturar financeiramente e se desenvolver ao longo do tempo.

Neste estudo, os indicadores de formação de redes estão alinhados aos de Ribeiro e Colauto (2016): grau de centralidade, adicionando-se a este a força de centralidade; grau de intermediação; tamanho do conselho, adicionando-se a este o tamanho da diretoria; e independência do conselho. Outros estudos utilizaram proxies similares para análise de redes por meio de board interlocking (Cunha \& Piccoli, 2017; Mendes-da-Silva, Rossoni, Martin \& Martelanc, 2008).

\subsection{Criação de valor em redes interorganizacionais e desenvolvimento das hipóteses}

Vínculos entre empresas, em que as aglomerações proporcionam um intenso relacionamento e são estimulados por entidades de governança, podem apontar fatores geradores de vantagem competitiva (Deboçã \& Martins, 2015). Entretanto, existe uma lacuna científica nacionalmente, considerando as questões controversas e inconclusivas nos estudos sobre o efeito da formação de redes interorganizacionais, por meio do board interlocking, no valor e desempenho da empresa (Santos \& Silveira, 2007; Kaczmarek et al., 2014).

Santos e Silveira (2007) constataram que a influência do board interlocking sobre o valor e o desempenho corporativo é negativa, indicando que a existência de um diretor executivo ou presidente do conselho que desempenha funções em outras empresas tende a reduzir o valor da firma. O estudo de Lamb (2017) também aponta que o número de conexões não influencia o desempenho financeiro de uma empresa.

Outro aspecto a se considerar dentro das redes é a criação e a troca de valor a partir da troca de aprendizagem. Marchi et al (2012) verificaram que, nas redes corporativas, a criação de valor é tão significativa quanto a troca de valor, demonstrando a existência de intenso nível de aprendizagem que permeia o ambiente das redes empresariais. 
De acordo com Vedel (2016), existe relevância sobre a estrutura de redes para a criação de valor empresarial, confirmado em estudos empíricos. Nesse sentido, e fundamentado na teoria da Dependência de Recursos, as organizações formam relacionamentos interorganizacionais a fim de exercer poder ou controle sobre outras organizações que possuem os recursos escassos, alinhando seus próprios interesses com os interesses dos stakeholders e reduzindo as incertezas ambientais, buscando, dessa forma, absorver a maior quantidade possível de conhecimento, aumentando as competências organizacionais e agregando valor para si e para os seus stakeholders (Larentis et al., 2014, Pfeffer \& Salancik, 1978).

Para os fins desta investigação, os indicadores de criação de valor estão alinhados com as variáveis adotadas por Camargos e Barbosa (2009): Q de Tobin, Market to Book e Firm value.

Assim, com base nos indicadores de redes interorganizacionais e nas medidas de criação de valor, e nos preceitos da teoria da Dependência de Recursos, cuja premissa está no ambiente externo, considerase a necessidade dos recursos externos para o desenvolvimento organizacional e que o acesso a tais recursos é possibilitado quando as corporações estabelecem conexões entre si por meio dos membros da sua alta administração, agindo como redutor de incertezas e diminuição dos custos de transação (Pfeffer \& Salancik, 1978). Destarte, espera-se que as empresas conectadas em rede, por seus conselheiros e diretores, obtenham mais recursos para criar maior valor que as empresas isoladas, não conectadas. Portanto, são definidas as seguintes hipóteses: H1: Os indicadores de redes interorganizacionais estão positivamente relacionados com as medidas de criação de valor; e H2: As empresas participantes de redes interorganizacionais criam valor superior ao das demais empresas.

\section{Procedimentos Metodológicos}

A população da pesquisa abrange todas as 289 companhias não financeiras com ações negociadas na B3, em 30 de agosto de 2017. A não inclusão de empresas do setor financeiro (bancos, seguradoras e demais instituições financeiras) decorre da peculiaridade de suas operações e, consequentemente, de seus relatórios contábeis, diferenciando-se das demais empresas (Medeiros \& Mol, 2017). Para a definição da amostra, foram excluídas 71 empresas, cujos dados necessários para os cálculos das variáveis do estudo não foram disponibilizados, resultando em 218 empresas. Foram coletadas 15.611 observações das empresas da amostra e dos 2.080 conselheiros e diretores a elas vinculados, alusivas ao exercício de 2016. 
A Figura 1 reúne as medidas adotadas para a análise de redes interorganizacionais.

\begin{tabular}{|c|c|c|c|}
\hline Variável & Definição & Mensuração & $\begin{array}{c}\text { Fundamentação } \\
\text { teórica }\end{array}$ \\
\hline $\begin{array}{l}\text { Grau de } \\
\text { Centralidade } \\
\text { (Degree) }\end{array}$ & $\begin{array}{l}\text { Número de laços adjacentes de um } \\
\text { ator com outros participantes da } \\
\text { mesma rede (ligação direta) }\end{array}$ & $\begin{array}{l}\text { Proporção de atores (empresas) } \\
\text { presentes na rede, menos um }\end{array}$ & $\begin{array}{l}\text { Wasserman e Faust } \\
\text { (1994) }\end{array}$ \\
\hline $\begin{array}{l}\text { Força de } \\
\text { Centralidade } \\
\text { (Power_Degree) }\end{array}$ & $\begin{array}{l}\text { Número de conexões que uma } \\
\text { empresa mantém com outras(s) } \\
\text { por meio dos membros da alta } \\
\text { administração }\end{array}$ & $\begin{array}{l}\text { Soma das participações dos } \\
\text { membros da alta administração em } \\
\text { outra(s) empresa(s) }\end{array}$ & Bonacich (1987) \\
\hline $\begin{array}{l}\text { Grau de } \\
\text { Intermediação } \\
\text { (Betweenness) }\end{array}$ & $\begin{array}{l}\text { Interações de dois atores não } \\
\text { adjacentes (ligação indireta) }\end{array}$ & $\begin{array}{l}\text { Número de geodésicas (menor } \\
\text { distância que une dois pontos) } \\
\text { entre os pares de empresas, } \\
\text { dividido pelo número de } \\
\text { geodésicas entre as empresas que } \\
\text { compartilham um membro }\end{array}$ & $\begin{array}{l}\text { Freeman (1979); } \\
\text { Mendes-da-Silva } \\
(2011)\end{array}$ \\
\hline $\begin{array}{l}\text { Tamanho do } \\
\text { Conselho de } \\
\text { Administração e da } \\
\text { Diretoria Executiva } \\
\text { (Tam CA e DE) }\end{array}$ & $\begin{array}{l}\text { Delineamento da estrutura de } \\
\text { governança corporativa }\end{array}$ & $\begin{array}{l}\text { Logaritmo natural do número de } \\
\text { conselheiros e diretores de uma } \\
\text { empresa }\end{array}$ & $\begin{array}{l}\text { Silveira, Barros e } \\
\text { Famá (2003) }\end{array}$ \\
\hline $\begin{array}{l}\text { Independência } \\
\text { do Conselho de } \\
\text { Administração } \\
\text { (Independ) }\end{array}$ & $\begin{array}{l}\text { Medida do nível de independência } \\
\text { do conselho de administração }\end{array}$ & $\begin{array}{l}\text { Número de membros } \\
\text { independentes no Conselho de } \\
\text { Administração em relação ao } \\
\text { número total de membros }\end{array}$ & Freitas e Mol (2017) \\
\hline
\end{tabular}

Figura 1. Variáveis de redes interorganizacionais

Fonte: elaborada com base em Ribeiro e Colauto (2016).

Adicionalmente às análises da centralidade (Degree), foram feitas considerações sobre a capacidade de a empresa manter conexões com outras empresas, denominada força de centralidade (Power Degree), medida pela quantidade de conexões que uma empresa mantém com outras ao mesmo tempo, dentro da rede, por meio do board interlocking, compartilhando os membros da alta administração.

As informações relacionadas às variáveis operacionais de redes interorganizacionais foram retiradas dos formulários de referência das empresas, referentes a 2016 e disponíveis no website da B3. Para a análise da formação de redes, a partir do compartilhamento de conselheiros e diretores, foram utilizados os softwares Ucinet 6.644 e NetDraw 2.161. 
A Figura 2 apresenta os dados das variáveis operacionais consideradas para a análise da criação de valor corporativo, coletados na base Economática ${ }^{\circledR}$.

\begin{tabular}{|c|c|c|c|}
\hline Variável & Definição & Mensuração & Fundamentação teórica \\
\hline \multirow{2}{*}{ Q de Tobin (QT) } & \multirow{2}{*}{$\begin{array}{l}\text { Estimativa dos ativos intangíveis da } \\
\text { empresa (mercado, qualidade da } \\
\text { administração e oportunidade de } \\
\text { investimento) }\end{array}$} & \multirow{2}{*}{$\mathrm{QT}=\frac{\mathrm{VMAO}+\mathrm{VMAP}+\mathrm{DIVT}}{\mathrm{AT}}$} & \multirow{2}{*}{$\begin{array}{l}\text { Camargos e Barbosa } \\
\text { (2009); Fauver, Hung, Li e } \\
\text { Taboada (2017) }\end{array}$} \\
\hline & & & \\
\hline \multirow{2}{*}{ Market to Book (MB) } & \multirow{2}{*}{$\begin{array}{l}\text { Medida utilizada para indicar o } \\
\text { desprendimento entre o valor de } \\
\text { mercado e o contábil }\end{array}$} & VMAO + VMAP & \multirow{2}{*}{$\begin{array}{l}\text { Camargos e Barbosa } \\
\text { (2009); Carvalho, Maia, } \\
\text { Louzada e Gonçalves } \\
\text { (2017) }\end{array}$} \\
\hline & & PL & \\
\hline \multirow{2}{*}{ Firm Value (FV) } & \multirow{2}{*}{$\begin{array}{l}\text { Medida do capital dos sócios } \\
\text { (ações), de terceiros (dívidas) e } \\
\text { daquele decorrente das atividades } \\
\text { da empresa em relação aos seus } \\
\text { investimentos }\end{array}$} & \multirow{2}{*}{$\mathrm{FV}=-$} & \multirow{2}{*}{$\begin{array}{l}\text { Camargos e Barbosa } \\
\text { (2009); Silveira, Barros e } \\
\text { Famá (2003) }\end{array}$} \\
\hline & & & \\
\hline \multicolumn{4}{|c|}{$\begin{array}{l}\text { Notas: QT - A fórmula se fundamenta nos testes comparativos do poder de explicação do método de estimação, que } \\
\text { explica pelo menos } 96,6 \% \text { dos valores do QT original; VMAO = Valor de Mercado de Ações Ordinárias; VMAP = Valor de } \\
\text { Mercado de Ações Preferenciais; DIVT = Valor contábil da Dívida Total, definida por: Passivo Circulante + Exigível a Longo } \\
\text { Prazo + Estoques - Ativo Circulante; AT = Ativo; PL = Patrimônio Líquido; Firm Value = VMAO + VMAP + DbCP + DbLP + } \\
\text { FinCP + FinLP + ACC - DICP. Onde: DbCP e DbLP = Debêntures de Curto e Longo Prazo; FinCP e FinLP = Financiamentos } \\
\text { de Curto e Longo Prazo; ACC = Adiantamentos de Contratos de Câmbio; DICP = Disponibilidades e Investimentos de } \\
\text { Curto Prazo. }\end{array}$} \\
\hline
\end{tabular}

Figura 2. Variáveis operacionais como proxies de criação de valor corporativo

Fonte: elaborada com base em Camargos e Barbosa (2009).

Outras variáveis são consideradas para fortalecer as análises e possibilitar a caracterização das empresas que formam redes, como: setor econômico, segmento de listagem, total de membros do conselho de administração e da diretoria executiva, gênero do participante da alta administração (conselheiros e diretores), idade média dos membros do conselho e da diretoria e dualidade de conselheiros e diretores.

O objetivo principal do estudo, que está vinculado à hipótese $\mathrm{H} 1$, é verificado com o uso da técnica de análise de correlação. $\mathrm{O}$ objetivo adicional de analisar as características das redes interorganizacionais é alcançado por meio da técnica de estatística descritiva, com medidas de tendência central, dispersão e distribuição de frequências e pelos indicadores específicos de redes sociais. Para o objetivo adicional de comparar a criação de valor entre as empresas que participam de redes interorganizacionais e as não participantes (hipótese H2), faz-se uso de teste de comparação de médias, separando as empresas em dois grupos (participantes de redes e não participantes). Utilizada ainda a técnica de árvore de regressão, adotando-se o método de detecção de interação automática do qui-quadrado (chaid), para identificar as características das empresas participantes de redes que apresentam maior probabilidade de criação de valor corporativo. 


\section{Apresentação e Análise dos Resultados}

\subsection{Análise das redes interorganizacionais}

Ao se analisar 218 empresas e seus 2.080 conselheiros e diretores, observa-se que 148 companhias $(67,9 \%)$ participam de redes interorganizacionais por meio da prática de board interlocking, enquanto $70(32,1 \%)$ não o praticam, sendo, portanto, excluídas desta parte inicial das análises, voltada para os indicadores de redes. Cenário semelhante foi encontrado por Santos e Silveira (2007), em que 74\% das empresas possuíam pelo menos um conselheiro proveniente de outra empresa, ou seja, praticavam interlocking.

A Figura 3 apresenta o grafo resultante das conexões entre as empresas, após a organização dos dados em matriz quadrada nos softwares Ucinet (inputs) e Netdraw (outputs).

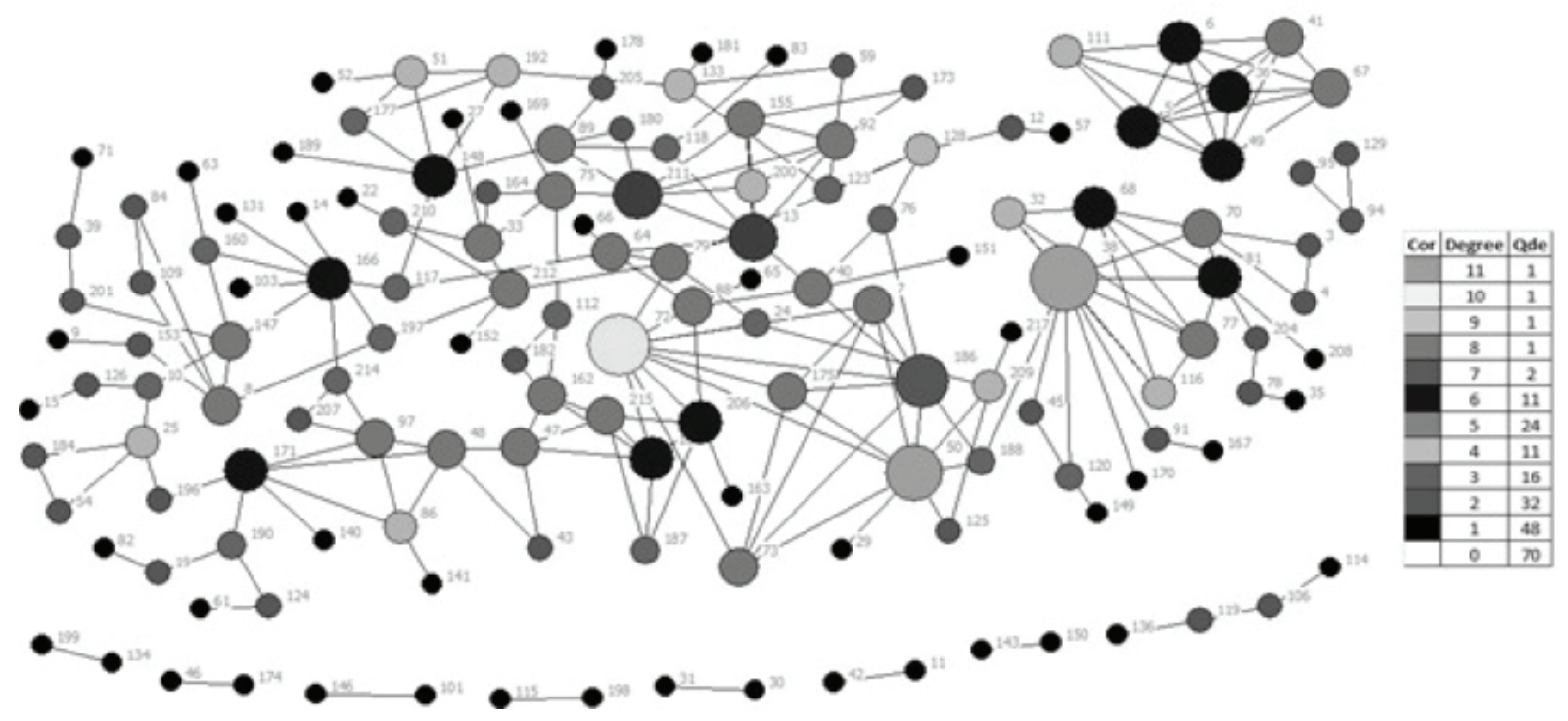

Figura 3. Grafo das redes interorganizacionais entre empresas listadas na B3

A Figura 3 exibe um emaranhado de linhas que ligam as empresas, representadas por nós, em diferentes quantidades de conexões. Explicita-se que os nós - em formato de círculos - representam as empresas conectadas dentro da rede. Os tamanhos e tons dos nós variam de acordo com as quantidades de interconexões que realizam na rede, que representa o grau de centralidade (degree); quanto mais se relacionam com outras empresas, maiores são os nós. Os tons estão definidoss pela medida de degree de cada empresa dentro da rede. Nota-se ainda que, além de uma grande rede formada pelas empresas, há outras sub-redes menores, de pares, de trios e outra com sete empresas. Esse fenômeno pode ocorrer, devido a acordos e parcerias entre empresas de mesmo setor, para facilitar a comunicação entre elas. Em outros casos, são empresas coligadas ou elos entre controladas e controladoras.

O grau de centralidade (centrality degree) equivale ao número de atores aos quais um ator se conecta diretamente, dividindo-se em grau de entrada (soma das interações dos outros nós com o ator) e grau de saída (soma das interações dos atores com os outros), dependendo da direção dos fluxos (Bloodgood, Hornsby, Rutherford \& McFarland, 2017). Para os fins da rede analisada, o grau de centralidade de uma empresa equivale à quantidade de suas conexões com outras, por meio da prática de board interlocking, ou seja, referente à quantidade de membros do conselho de administração e da diretoria executiva que participam de duas ou mais empresas ao mesmo tempo, independentemente da direção da conexão. 
Adicionalmente à centralidade, foi possível analisar a capacidade de um ator de estabelecer conexões com outros atores, medida pela força de centralidade, denominada power degree, que, neste estudo, equivale à quantidade de conexões de uma empresa com outras empresas ao mesmo tempo, por meio da prática de board interlocking.

Em relações de grupos sociais, a probabilidade de uma informação propagar-se em uma rede é proporcional à força de seus laços (Homans, 1950), que pode ser estimada pela frequência de conexões. A Tabela 1 mostra a distribuição do degree e do power degree.

Tabela 1

Distribuição de graus de centralidade e de força de centralidade na rede.

\begin{tabular}{|c|c|c|c|c|c|c|c|c|c|}
\hline \multicolumn{5}{|c|}{ Grau de centralidade (degree) } & \multicolumn{5}{|c|}{ Força de centralidade (power degree) } \\
\hline Degree & Freq. & Proporção (\%) & Acumulado & $\begin{array}{c}\text { Acumulado } \\
\text { (\%) }\end{array}$ & $\begin{array}{l}\text { Power } \\
\text { degree }\end{array}$ & Freq. & Proporção (\%) & Acumulado & Acumulado (\%) \\
\hline 11 & 1 & 0,5 & 1 & 0,5 & 28 & 2 & 0,9 & 2 & 0,9 \\
\hline 10 & 1 & 0,5 & 2 & 0,9 & 26 & 1 & 0,5 & 3 & 1,4 \\
\hline 9 & 1 & 0,5 & 3 & 1,4 & 23 & 1 & 0,5 & 4 & 1,8 \\
\hline 8 & 1 & 0,5 & 4 & 1,8 & 20 & 1 & 0,5 & 5 & 2,3 \\
\hline 7 & 2 & 0,9 & 6 & 2,8 & 16 & 2 & 0,9 & 7 & 3,2 \\
\hline 6 & 11 & 5,0 & 17 & 7,8 & 14 & 2 & 0,9 & 9 & 4,1 \\
\hline 5 & 24 & 11,0 & 41 & 18,8 & 13 & 4 & 1,8 & 13 & 6,0 \\
\hline 4 & 11 & 5,0 & 52 & 23,9 & 12 & 2 & 0,9 & 15 & 6,9 \\
\hline 3 & 16 & 7,3 & 68 & 31,2 & 11 & 3 & 1,4 & 18 & 8,3 \\
\hline 2 & 32 & 14,7 & 100 & 45,9 & 10 & 2 & 0,9 & 20 & 9,2 \\
\hline 1 & 48 & 22,0 & 148 & 67,9 & 9 & 2 & 0,9 & 22 & 10,1 \\
\hline \multirow[t]{9}{*}{0} & 70 & 32,1 & 218 & 100,0 & 8 & 4 & 1,8 & 26 & 11,9 \\
\hline & & & & & 7 & 11 & 5,0 & 37 & 17,0 \\
\hline & & & & & 6 & 7 & 3,2 & 44 & 20,2 \\
\hline & & & & & 5 & 13 & 6,0 & 57 & 26,1 \\
\hline & & & & & 4 & 18 & 8,3 & 75 & 34,4 \\
\hline & & & & & 3 & 17 & 7,8 & 92 & 42,2 \\
\hline & & & & & 2 & 27 & 12,4 & 119 & 54,6 \\
\hline & & & & & 1 & 29 & 13,3 & 148 & 67,9 \\
\hline & & & & & 0 & 70 & 32,1 & 218 & 100,0 \\
\hline
\end{tabular}

Entre as empresas participantes de redes, a Cemig apresentou o maior degree da amostra, realizando 11 conexões pela prática de board interlocking de membros do conselho e da diretoria. Na sequência, aparece a Embraer (10), a Coteminas (9), a Springs (8), a Arezzo (7) e a Valid (7). As 70 empresas com degree zero são aquelas que não se ligam a nenhuma outra empresa.

Verifica-se que, na rede, a medida máxima de compartilhamento dos membros da alta administração com outras empresas (power degree) foi assinalada pela Afluente e pela Afluente-T, ambas com 28, seguidas por Celpe (26), Cosern (23), Coelba (20), Cemig (16), Coteminas (16), Springs (14) e AES Tietê-E (14).

Para os fins da rede analisada, a capacidade de intermediação equivale à quantidade de vezes que uma empresa aparece intermediando a ligação de outras duas empresas, podendo servir como ponte de comunicação entre pares de empresas. A Tabela 2 exibe a distribuição de frequências dessa medida, por classe de graus de intermediação (betweness) da rede. 
Tabela 2

Distribuição de graus de intermediação (betweness) na rede

\begin{tabular}{|c|c|c|c|c|c|c|}
\hline \multicolumn{3}{|c|}{ Classe de betweness } & \multirow{2}{*}{$\frac{\text { Freq. }}{3}$} & \multirow{2}{*}{$\frac{\text { Proporção (\%) }}{1,4}$} & \multirow{2}{*}{$\frac{\text { Freq. acumulada }}{3}$} & \multirow{2}{*}{$\frac{\text { Proporção acumulada (\%) }}{1,4}$} \\
\hline 1734 & $|--|$ & 2022 & & & & \\
\hline 1445 & 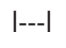 & 1733 & 3 & 1,4 & 6 & 2,8 \\
\hline 1156 & 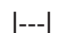 & 1444 & 5 & 2,3 & 11 & 5,0 \\
\hline 867 & |---| & 1155 & 5 & 2,3 & 16 & 7,3 \\
\hline 578 & 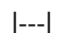 & 866 & 6 & 2,8 & 22 & 10,1 \\
\hline 289 & |---| & 577 & 11 & 5,0 & 33 & 15,1 \\
\hline 1 & 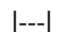 & 288 & 34 & 15,6 & 67 & 30,7 \\
\hline 0 & |--| & 0 & 151 & 69,3 & 218 & 100,0 \\
\hline
\end{tabular}

A Embraer é a empresa que apresentou maior capacidade de intermediação e de servir como canal de comunicação entre pares de empresas, com medida de betweness 2.015 , ou seja, funcionando como ponte entre pares de empresas em 2.015 vezes (combinações). Na sequência, por ordem decrescente de graus de betweness, destacam-se ainda Cemig (1.908), Taesa (1.900), Klabin (1.505), Raiadrogasil (1.490), Estácio Part (1.460) e Springs (1.444). Das 218 empresas da amostra, 151 não apresentaram nenhum papel de intermediação, estando inclusas nestas as 70 que não apresentam nenhuma medida de centralidade, observado na Tabela 1.

Essa medida mostra a centralidade de intermediação (betweenness) de todas as empresas estudadas, demonstrando ser a Embraer a empresa que desenvolve esse papel de forma mais eficientemente dentro da rede investigada.

Uma medida relevante para a análise do relacionamento entre empresas em rede é a quantidade de membros na alta administração e a independência dos membros do conselho. Para Ribeiro e Colauto (2016) e Santos e Silveira (2007), o tamanho do conselho e outsiders tendem a influenciar positivamente as práticas de redes sociais, havendo correlação positiva entre laços indiretos (betweenness) e o tamanho do conselho.

Quanto à independência do conselho de administração, que equivale ao número de membros independentes do colegiado, Freitas e Mol (2017) destacam a relevância do seu grau para o estudo de subordinações e relacionamentos empresariais. Para os fins desse estudo, destaca-se que a análise considera a soma de membros titulares do conselho de administração e da diretoria executiva. A Tabela 3 mostra as classes de frequência da quantidade de membros na alta administração, assim como o número de conselheiros independentes nas estruturas administrativas das empresas.

Tabela 3

Distribuição de frequência em classes do tamanho do conselho de administração e da diretoria executiva e independência do conselho de administração

\begin{tabular}{|c|c|c|c|c|c|c|c|c|c|c|c|c|c|}
\hline \multicolumn{7}{|c|}{$\begin{array}{l}\text { Tamanho do Conselho de Administração e da Diretoria } \\
\text { Executiva }\end{array}$} & \multicolumn{7}{|c|}{$\begin{array}{l}\text { Número de Membros Independentes no Conselho de } \\
\text { Administração }\end{array}$} \\
\hline \multicolumn{3}{|c|}{ Classe } & \multirow{2}{*}{$\begin{array}{c}\text { Freq. } \\
7\end{array}$} & \multirow{2}{*}{$\begin{array}{c}\text { Proporção } \\
\text { (\%) }\end{array}$} & \multirow{2}{*}{$\begin{array}{c}\begin{array}{c}\text { Freq. } \\
\text { Acumulada }\end{array} \\
7\end{array}$} & \multirow{2}{*}{$\begin{array}{c}\begin{array}{c}\text { Proporção } \\
\text { Acumulada (\%) }\end{array} \\
3,2\end{array}$} & \multicolumn{3}{|c|}{ Classe } & \multirow{2}{*}{$\frac{\text { Freq. }}{1}$} & \multirow{2}{*}{$\begin{array}{c}\text { Proporção } \\
(\%)\end{array}$} & \multirow{2}{*}{$\begin{array}{c}\begin{array}{c}\text { Freq. } \\
\text { Acumulada }\end{array} \\
1\end{array}$} & \multirow{2}{*}{$\begin{array}{c}\text { Proporção } \\
\text { Acumulada (\%) } \\
0,5\end{array}$} \\
\hline 20 & |---| & 23 & & & & & 8 & |---| & 9 & & & & \\
\hline 16 & |---| & 19 & 24 & 11,0 & 31 & 14,2 & 6 & |---| & 7 & 9 & 4,1 & 10 & 4,6 \\
\hline 12 & |---| & 15 & 58 & 26,6 & 89 & 40,8 & 4 & |---| & 5 & 33 & 15,1 & 43 & 19,7 \\
\hline 8 & |---| & 11 & 75 & 34,4 & 164 & 75,2 & 2 & |---| & 3 & 75 & 34,4 & 118 & 54,1 \\
\hline 4 & |---| & 7 & 51 & 23,4 & 215 & 98,6 & 0 & |--| & 1 & 100 & 45,9 & 218 & 100,0 \\
\hline 0 & |---| & 3 & 3 & 1,4 & 218 & 100,0 & & & & & & & \\
\hline
\end{tabular}


Em relação ao tamanho da alta administração, a Cemig foi a empresa que apresentou o maior número de membros, (23), seguida por Ambev (21), Braskem (21), Coelce (21), Weg (21), Alliar (20), Celesc (20), Ceg (19) e Klabin (19).

Quanto à independência do conselho de administração, destaca-se a Estácio Par, com 9 membros independentes, seguida por Embraer, Lojas Rener e Eternit, com 7, cada. Das 218 empresas da amostra, $75(34,4 \%)$ não possuem nenhum membro independente no colegiado.

A densidade da rede resultou no índice $0,93 \%$, ou seja, de todas as 47.534 possibilidades de conexão entre as 218 empresas, ocorreram 442. Essa medida de densidade pode impactar a velocidade de difusão de informações ou a extensão de ameaças e oportunidades que a rede pode oferecer para as empresas conectadas. A densidade da rede é considerada baixa (Bloodgood et al., 2017). Para Watts e Strogatz (1998), quanto maior a densidade local da rede, que varia de 0 a 1 , maior é a densidade. Assim, quando as empresas estão mais bem aninhadas, apresentam maiores benefícios a partir da coesão da rede; quando a densidade é baixa, diz-se que a rede é esparsa ou não densa (Obstfeld, 2005).

Destaca-se que, na amostra, o maior índice de centralidade de uma empresa na rede foi de $4,17 \%$, sendo considerado baixo, já que tal indicador pode variar de $0 \%$ a $100 \%$. Conforme Provan, Fish e Sydow (2007), o índice de centralização da rede mostra a dificuldade de integração da rede por um agente centralizador, já que a existência de um grande número de ligações não garante que a rede é centralizada.

\subsection{Análise descritiva}

A Tabela 4 expõe a estatística descritiva das principais variáveis do estudo.

Tabela 4

\section{Estatística descritiva das variáveis do estudo}

\begin{tabular}{|c|c|c|c|c|c|}
\hline Variável & $\begin{array}{l}\mathrm{N}^{\circ} \text { de } \\
\text { empresas }\end{array}$ & Mínimo & Máximo & Média & Desvio-padrão \\
\hline Rede (Board Interlocking) & 218 & 0 & 1 & 0,679 & 0,468 \\
\hline Dualidade (CEO e Chairman) & 218 & 0 & 1 & 0,119 & 0,325 \\
\hline $\begin{array}{l}\text { Número de membros do conselho de } \\
\text { administração }\end{array}$ & 218 & 0 & 14 & 6,794 & 2,472 \\
\hline $\begin{array}{l}\text { Número de membros da diretoria } \\
\text { executiva }\end{array}$ & 218 & 1 & 14 & 4,734 & 2,397 \\
\hline $\begin{array}{l}\text { Número de membros no conselho de } \\
\text { administração e na diretoria executiva }\end{array}$ & 218 & 0 & 23 & 10,784 & 4,215 \\
\hline Centralidade (Degree) & 218 & 0 & 11 & 2,028 & 2,210 \\
\hline Intermediação (Betweness) & 218 & 0 & 2.015 & 159,729 & 372,208 \\
\hline Q de Tobin & 218 & $-583,262$ & $1.358,662$ & 20,844 & 158,781 \\
\hline Market To Book & 218 & 0,000 & 76,267 & 2,053 & 5,606 \\
\hline Firm Value & 218 & $-1.608,121$ & 503,974 & 2,764 & 123,201 \\
\hline
\end{tabular}

A proxy para Rede é dicotômica, com valor 1 se a empresa participa de rede e valor nulo no caso contrário, demonstrando que das 218 empresas 148 (67,9\%) se inter-relacionam por meio da prática de board interlocking. A variável Dualidade também é dicotômica, com o valor 1 se o mesmo profissional que exerce o cargo de CEO exerce a função de presidente do conselho de administração (Chairman), e valor nulo no caso contrário, evidenciando-se que essa prática ocorre em 27 empresas (12,4\%). Nota-se ainda que, em média, os conselhos das empresas reúnem aproximadamente 7 pessoas, e a diretoria executiva possui 5 membros. 
A variável Degree representa, neste estudo, a quantidade de conexões de uma empresa com outras empresas pela prática de board interlocking. Verifica-se que o valor máximo encontrado na rede foi de uma empresa conectada com outras 11, enquanto, na média, o grau de centralidade na rede equivale a, aproximadamente, duas conexões.

Quanto à medida Power Degree, foi observado o máximo de 28 compartilhamentos de conselheiros e diretores de uma empresa com outras, enquanto na rede, em média, essa medida ficou em torno de 3 compartilhamentos de membros.

A variável Betweness retrata as conexões de duas empresas por intermédio de uma outra empresa, sendo observado um número máximo de 2.015 pontes de conexões entre pares de empresas, enquanto na rede, em média, essa medida apresenta em torno de 160 pontes.

Verifica-se que, entre as três medidas de criação de valor corporativo, o Market to Book é a que apresenta menor dispersão e uma maior homogeneidade dos dados. Tais variáveis são indispensáveis para testar as hipóteses do estudo e analisar seus resultados.

\subsection{Testes das hipóteses da pesquisa}

Inicialmente, para se verificar a H1, fez-se uso da análise de correlação entre os indicadores de redes interorganizacionais e às medidas de criação de valor. As referidas variáveis foram previamente testadas quanto à normalidade dos dados, por meio dos testes de Kolmogorov-Smirnov e Shapiro-Wilk, e, em ambos os testes, todas as variáveis apresentaram distribuição dos dados diferente da normal, com $p$ value de 0,000. Assim, considerando-se a não normalidade dos dados, aplicou-se o teste de Correlação não Paramétrico, de Spearman, para verificação das associações (Tabela 5).

Tabela 5

Teste de correlação não paramétrico de Spearman

\begin{tabular}{|c|c|c|c|c|c|c|}
\hline Variáveis & Degree & Betweness & Board Intelocking & Q de Tobin & Market To Book & Firm Value \\
\hline Degree & 1 &, $619(* *)$ &, $825(* *)$ &, $181(* *)$ &, $228(* *)$ &, $224(* *)$ \\
\hline Betweness & & 1 &, $466(* *)$ &, $179\left(^{\star *}\right)$ &, $248(* *)$ &, $195(* \star)$ \\
\hline Board Interlocking & & & 1 &, $135\left(^{*}\right)$ &, $241(* *)$ &, $232(* *)$ \\
\hline Q de Tobin & & & & 1 &, $245(* *)$ &, $691(* *)$ \\
\hline Market to Book & & & & & 1 &, $341(* *)$ \\
\hline Firm Value & & & & & & 1 \\
\hline
\end{tabular}

Nota: ${ }^{*}$ ) Correlação significativa ao nível de 0,05; $\left({ }^{* *}\right)$ Correlação significativa ao nível de 0,01.

O teste revelou uma correlação entre as três medidas de redes interorganizacionais, assim como entre as três medidas de criação de valor consideradas, demonstrando que as medidas que se dedicam a representar as respectivas variáveis estão associadas entre si, confirmando a mesma tendência na representação das variáveis. Verificou-se também correlações cruzadas entre as variáveis representativas de redes e aquelas representativas de criação de valor, todas ao nível de significância de 1\%, com exceção da correlação entre o Board Interlocking e o Q de Tobin, que se deu ao nível de significância de 5\%. Dessa forma, há suporte para não rejeitar a hipótese H1, constatando-se haver correlação entre a formação de redes interorganizacionais e a criação de valor nas companhias abertas no Brasil. 
Esse resultado vai ao encontro dos achados de Mendes-da-Silva (2011), que indicou uma correlação significativa do grau de centralidade com o Q de Tobin e que o Degree normalizado foi significativo e positivamente relacionado com o valor da firma. Os resultados empíricos sugerem a existência de indícios para a associação do valor e do desempenho da firma com o posicionamento da empresa na rede de relações corporativas.

Para se comparar a criação de valor entre as empresas que praticam a formação de redes e as demais (hipótese H2), foi aplicado teste de comparação de médias, após a segregação das empresas em dois grupos: i) 148 empresas que formam redes por meio da prática de board interlocking; e ii) 70 empresas não participantes de redes.

A Tabela 6 expõe a estatística descritiva das medidas de criação de valor.

Tabela 6

Estatística descritiva das medidas de criação de valor entre os grupos de empresas

\begin{tabular}{cccccc}
\hline Criação de Valor & Rede & N & Média & Desvio-Padrão & Coeficiente de Variação \\
\hline \multirow{3}{*}{ Q de Tobin } & Total & 218 & 20,844 & 158,781 & 7,618 \\
& Participante & 148 & 31,033 & 178,593 & 5,755 \\
& Não Participante & 70 & $-0,699$ & 103,168 & $-147,594$ \\
\hline \multirow{3}{*}{ Market To Book } & Total & 218 & 2,053 & 5,606 & 2,730 \\
& Participante & 148 & 2,392 & 6,503 & 2,719 \\
& Não Participante & 70 & 1,337 & 2,821 & 2,110 \\
\hline \multirow{2}{*}{ Firm Value } & Total & 218 & 2,764 & 123,201 & 44,575 \\
& Participante & 148 & 13,946 & 67,579 & 4,846 \\
& Não Participante & 70 & $-20,878$ & 192,795 & $-9,234$ \\
\hline
\end{tabular}

$\mathrm{Na}$ Tabela 6, é possível observar que, dentre as três medidas de criação de valor consideradas, o Market to Book apresenta uma distribuição mais homogênea.

Como os testes de Kolmogorov-Smirnov e Shapiro-Wilk aplicados sobre todas as variáveis apresentaram distribuição diferente da normal, aplicou-se o teste de Comparação de Médias não paramétrico de Mann-Whitney (Tabela 7).

Tabela 7

Teste de comparação de médias não paramétrico de Mann-Whitney

\begin{tabular}{llcc}
\hline \multicolumn{1}{c}{ Testes - Hipótese nula } & Teste & Sig. & Resultado \\
\hline 1) $\begin{array}{l}\text { A distribuição de Q de Tobin é a mesma entre as empresas } \\
\text { participantes de redes interorganizacionais e as demais }\end{array}$ & $\begin{array}{c}\text { Teste U de } \\
\text { Mann-Whitney } \\
\text { de amostras } \\
\text { 2) } \begin{array}{l}\text { A distribuição de Market to Book é a mesma entre as empresas } \\
\text { participantes de redes interorganizacionais e as demais }\end{array}\end{array}$ & $\begin{array}{c}0,000 \\
\text { independentes }\end{array}$ & $\begin{array}{c}\text { Rejeita a } \\
\text { hipótese nula } \\
\text { para os três } \\
\text { testes }\end{array}$ \\
$\begin{array}{l}\text { 3) distribuição de Firm Value é a mesma entre as empresas } \\
\text { participantes de redes interorganizacionais e as demais }\end{array}$ & 0,001 & \\
\hline
\end{tabular}

Ao se observar as informações da Tabela 7, e considerando-se as medidas descritivas da Tabela 6, verifica-se que há suporte para não rejeitar a hipótese $\mathrm{H} 2$, pois nas três medidas de criação de valor, verificou-se um valor médio superior para as empresas participantes de redes interorganizacionais, em comparação com as empresas não participantes. 
Esse resultado alinha-se ao obtido por Mendes-da-Silva (2011), os quais apontam que, a partir da correlação da centralidade de grau com o $Q$ de Tobin, há valores que maximizam o valor da centralidade da empresa, no âmbito da rede.

Os achados demonstram que, fundamentado na teoria da Dependência de Recursos, as empresas formam redes entre si, como forma de executarem suas estratégias empresariais, acessando recursos externos e criando valor corporativo para si e para os seus stakholders, no ambiente cada vez mais competitivo.

Destaca-se, contudo, que esses resultados contrariam os achados de Santos e Silveira (2007), que, segundo os quais, a prática do board interlocking é prejudicial ao valor da companhia, mensurado pelo Q de Tobin e pela capitalização de mercado.

\subsection{Análise multivariada (árvore de regressão)}

Adicionalmente, visando maior robustez da análise da correlação entre a prática de formação de redes interorganizacionais e a criação de valor, estabelece-se uma metodologia de análise em árvore de regressão, utilizando o algoritmo de seleção das variáveis pelo método de deteç̧ão de interação automática do qui-quadrado (chaid). Dentre os três indicadores de criação de valor considerados, o Market to Book foi definido como a medida representativa da criação de valor para esta análise, pelo fato de, em comparação com o Q de Tobin e o Firm Value, apresentar-se mais homogênea (Tabela 6).

Assim, o valor do Market to Book foi a medida escolhida como variável dependente da árvore, e as variáveis verificadas como explicativas foram: degree, power degree, betweness, tamanho do conselho de administração e da diretoria executiva e independência do conselho de administração. A Figura 4 apresenta a árvore de regressão (método chaid) da rede.

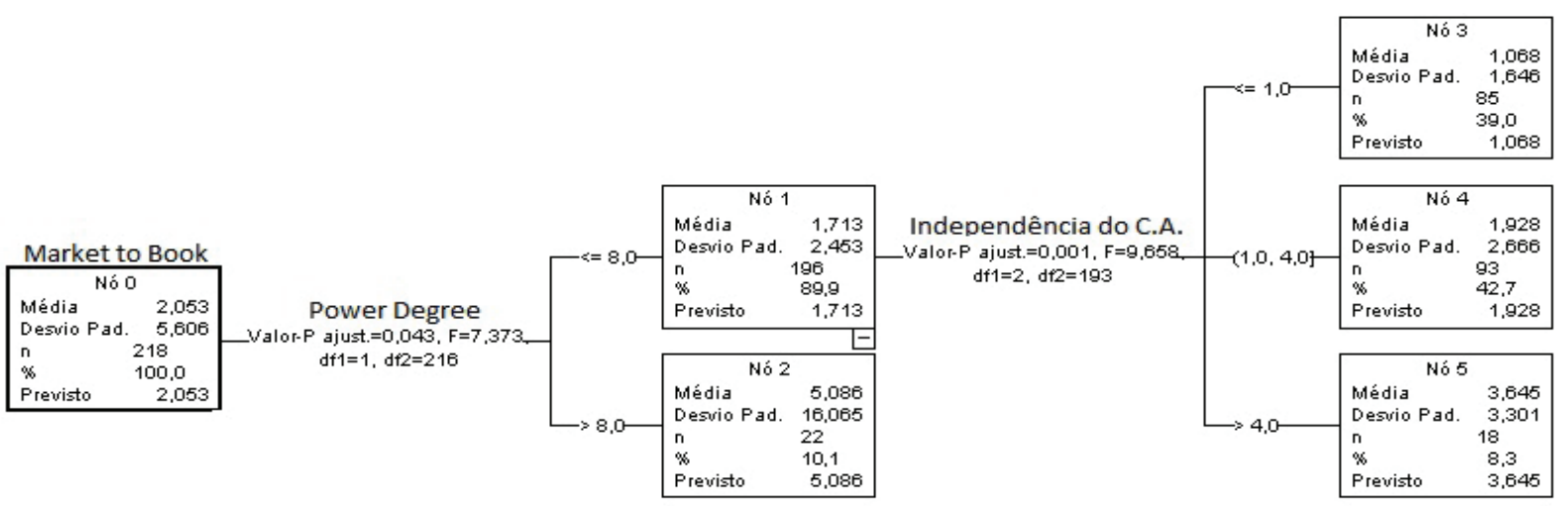

Figura 4. Árvore de regressão (método chaid) da rede com impacto no Market to Book

As variáveis testadas como independentes, degree, betweness, tamanho do conselho de administração e da diretoria executiva não apresentaram probabilidade significativa na árvore de regressão a ponto de caracterizar as empresas que criam valor medido pelo Market to Book.

Partindo da análise dos valores da medida Market to Book das 218 empresas (nó 0), nota-se que a árvore resulta em cinco nós de regressão. Na primeira subdivisão, a partir da característica de força de centralidade (power degree), as empresas foram cindidas em dois nós, o primeiro formado por empresas que possuem até o valor 8 de poder de centralidade (power degree) (nó 1), e o segundo com menos de 8 (nó 2), com p-value de 0,043 . No nó 1 , a árvore regrediu em outros três nós, com base na quantidade de membros independentes na composição do conselho, com p-value de 0,001. Nessa subdivisão, ficaram empresas com até um conselheiro independente (nó 3), 2 a 4 (nó 4) e mais de 4 (nó 5). 
Assim, é possível inferir, a partir da estrutura resultante da árvore regredida, as prováveis variáveis e medidas que contribuem para a criação de valor das empresas, no caso aquelas participantes de redes cujos conselhos de administração têm entre 2 e 4 membros independentes, com probabilidade de 42,7\% (nó 4); e com valor máximo de 8 interlocking em força/capacidade de centralidade (power degree), com probabilidade de $89,9 \%$ (nó 1 ).

Esses achados são similares aos de Santos e Silveira (2007), segundo os quais o valor da companhia pode ficar prejudicado por altos níveis de interlocking, como nas empresas cuja metade ou mais dos conselheiros atua em três ou mais conselhos, identificando que o ponto ideal de interlocking é de até 5 ligações por empresa.

Diante do exposto, com base na teoria da Dependência dos Recursos, verificou-se que as empresas que praticam o board interlocking - forma pela qual as empresas participam de redes interorganizacionais - possuem, em média, valores superiores de medidas de criação de valor aos valores das demais empresas. Além disso, percebeu-se associação positiva entre os indicadores de redes interorganizacionais e as medidas de criação de valor corporativo.

\section{Considerações Finais}

Investigaram-se as relações entre a prática de formação de redes interorganizacionais e a criação de valor corporativo no âmbito de 218 companhias listadas na B3, e ficou evidenciada a predominância de interconexões entre as empresas, com 148 companhias (67,9\%) participantes de redes, confirmando que no Brasil o board interlocking é uma prática recorrente entre as companhias abertas.

Dentre as características das redes e das empresas participantes, foi possível evidenciar medidas de centralidade (degree), intermediação (betweness), densidade e centralização, assim como nos estudos de Cunha e Piccoli (2017) e Mendes-da-Silva et al. (2008), que evidenciaram empresas que concentram a maioria das conexões entre as redes formadas, influenciando os indicadores e medidas nas redes.

Constatou-se que quanto maior é o número de membros do conselho de administração e da diretoria executiva, maior é a prática de board interlocking entre as empresas. Assim como a independência do conselho pode deixar os membros livres para participarem de conselhos e diretorias de outras empresas, influenciando a formação de redes sociais corporativas e, consequentemente, a troca de recursos e criação de valor corporativo, corroborando os estudos de Fich e White (2005) e Santos e Silveira (2007).

As duas hipóteses da pesquisa foram confirmadas, já que foi possível verificar a existência de correlação entre todas as variáveis de redes interorganizacionais com todas as variáveis de criação de valor consideradas no estudo. Assim como se constatou que nas empresas que formam redes interorganizacionais, por meio da prática de board interlocking, as medidas de criação de valor são superiores às das demais empresas.

Os resultados da pesquisa trazem implicações para a compreensão da contribuição positiva das redes interorganizacionais, pela prática de board interlocking, na criação de valor das empresas. Os achados mostram que a relação é positiva, porém torna-se prejudicial se houver excesso de conselheiros independentes (acima de 4) e de compartilhamentos de seus profissionais (acima de 8) com outras empresas.

Para Santos e Silveira (2007), o ponto ideal de interlocking para as variáveis de desempenho é de até 5 ligações por empresa, enquanto que, neste estudo, o limite foi de 8 interlocking por empresa, para contribuir com a criação de valor, sugerindo que o fator temporal, a amostra e as medidas consideradas no estudo podem ter contribuído para tais diferenças, motivando, assim, estudos futuros para comparação de resultados. 
Com base na teoria da Dependência de Recursos, verificou-se, portanto, que as empresas conectadas em rede, por meio da prática de board interlocking, podem contribuir para melhorar a atividade econômica umas das outras, por meio da troca de recursos e redução de incertezas (Ribeiro et al. 2016). Assim como a existência e eficiência de laços corporativos apoiam a criação de valor corporativo (Mendes-da-Silva, 2011).

Diante do exposto, pode-se depreender que as empresas conectam-se entre si para acessar recursos externos, assegurar a execução de suas estratégias empresariais e criar valor corporativo superior para si e para seus stakeholders. A pesquisa alcançou, portanto, os objetivos estabelecidos, apresentando uma visão específica de relacionamentos entre os dois construtos analisados.

A pesquisa fornece ainda subsídios para a definição de práticas de governança corporativa e para políticas fiscalizatórias de órgãos reguladores quanto ao limite de prática de board interlocking, que impacta na qualidade dos serviços dos administradores profissionais.

O estudo não explora com profundidade análises qualitativas das redes sociais formadas pelas companhias abertas brasileiras e não considera a influência do segmento financeiro nas redes constituídas. Dessa forma, sugere-se, para futuros estudos, que sejam consideradas as inter-relações de empresas financeiras com empresas de outros setores e do mesmo setor, a fim de analisar o efeito dessas relações, as motivações e os efeitos, tanto na criação de valor das empresas, quanto no desempenho econômicofinanceiro dentro da rede, além de considerar uma análise longitudinal, para se verificar a evolução dos efeitos no tempo.

\section{Referências}

Almeida, L. F. \& Machado, C. A. P., Filho. (2013). Competências compartilhadas em alianças estratégicas: um estudo da aliança Cosan e Shell no mercado de biocombustíveis. Revista de Administração da Universidade de São Paulo, 48(2), pp. 359-374. doi: http://dx.doi.org/10.5700/rausp1093.

Aranha, C., Rossoni, L. \& Mendes-da-Silva, W. (2016). Capital social do conselho de administração e desempenho de empresas de capital aberto brasileiras. Revista de Administração Mackenzie, 17(1), pp. 15-39. doi: http://dx.doi.org/10.1590/1678-69712016/administracao.v17n1p15-39.

Balestrin, A., Verschoore, J. R. \& Reyes, E., Júnior. (2010). O campo de estudo sobre redes de cooperação interorganizacional no Brasil. Revista de Administração Contemporânea, 14(3), pp. 458-477. doi: http://dx.doi.org/10.1590/S1415-65552010000300005.

Bloodgood, J. M., Hornsby, J. S., Rutherford, M. \& McFarland, R. G. (2017). The role of network density and betweenness centrality in diffusing new venture legitimacy: an epidemiological approach. International Entrepreneurship and Management Journal, 13(2), pp. 525-552. doi: 10.1007/s11365016-0412-9

Bonacich, P. (1987). Power and centrality: a family of measures. American Journal of Sociology, 92(5), pp. 1170-1182. doi: $10.1086 / 228631$

Camargos, M. A. \& Barbosa, F. V. (2009). Fusões e aquisições de empresas brasileiras: criação de valor e sinergias operacionais. Revista de Administração de Empresas, 49(2), pp. 206-220. doi: https://dx.doi. org/10.1590/S0034-75902009000200007

Carvalho, F. P. de, Maia, V. M., Louzada, L. C. \& Gonçalves, M. A. (2017). Desempenho setorial de empresas brasileiras: um estudo sob a ótica do ROE, Q de Tobin e Market to Book. Revista de Gestão, Finanças e Contabilidade, 7(1), pp. 149-163. doi: http://dx.doi.org/10.18028/rgfc.v7i1.3052 
Cunha, P. R. da \& Piccoli, M. R. (2017). Influência do board interlocking no gerenciamento de resultados. Revista Contabilidade \& Finanças, 28(74), 179-196.

https://doi.org/10.1590/1808-057x201701980

Deboçã, L. P. \& Martins, R. S. (2015). Vantagens Competitivas Originadas dos Relacionamentos Horizontais em Aglomerações Produtivas: percepções de atores locais. Revista Brasileira de Gestão de Negócios, 17(56), pp. 1025-1043. doi: http://dx.doi.org/10.7819/rbgn.v17i56.1848.

Fauver, L., Hung, M., Li, X. M. H. \& Taboada, A. G. (2017). Boards reform and firm value: worldwide evidence. Journal of Financial Economics, 125(1), pp. 120-142. doi: https://doi.org/10.1016/j. jfineco.2017.04.010

Fich, E. M. \& White, L. J. (2005). Why do CEOs reciprocally sit on each other's boards? Journal of Corporate Finance, 11(1-2), pp. 175-195. doi: http://dx.doi.org/10.2139/ssrn.249975

Freeman, L. C. (1979). Centrality in social networks: conceptual clarification. Social Networks, 1(2), pp. 215-239.

Freitas, R. M. D., Neto \& Mol, A. L. R. (2017). Determinants of the roles boards of directors have in Brazilian companies. Revista de Administração Contemporânea, 21 a(Ed. Esp.), pp. 63-83. doi: http:// dx.doi.org/10.1590/1982-7849rac2017160053

Gobibi, B. C., Cunha, E. P., Brito, M. J. D. \& Senger, I. (2005). Politizando o conceito de redes organizacionais: uma reflexão teórica da governança como jogo de poder. Cadernos Ebape.BR, 3(1), pp. 1-16. doi: http://dx.doi.org/10.1590/S1679-39512005000100004

Hillman, A., Cannella, A. \& Paetzold, R. (2000). The resource dependence role of corporate directors: strategic adaptation of board composition in response to environmental change. Journal of Management Studies, 37(2), pp. 235-256. doi: https://doi.org/10.1111/1467-6486.00179

Homans, G. C. (1950). The human group. New York: Harcourt, Brace and World.

Kaczmarek, S.; Kimino, S. \& Pye, A. (2014). Interlocking directorships and firm performance in the highly regulated sectors: the moderating impact of board diversity. Journal of Management \& Governance, 18(2), pp. 347-372. doi: https://doi.org/10.1007/s10997-012-9228-3

Lamb, N. H. (2017). Does the number of interlocking directors influence a firm's financial performance? An exploratory meta-analysis. American Journal of Management, 17(2), pp. 47-57. doi: https://doi. org/10.33423/ajm.v17i2.1757

Larentis, F., Antonello, C. S., Milan, G. S. \& De Toni, D. (2014). Aprendizagem organizacional e relacionamentos interorganizacionais: um estudo de casos múltiplos. BASE - Revista de Administração e Contabilidade da Unisinos, 11(4), pp. 347-366. doi: 10.4013/base.2014.114.06

Marchi, J. J., Cassanego, P., Júnior \& Wittmann, M. L. (2012). Troca e criação de valor: possibilidades competitivas advindas da estratégia de redes. Revista de Administração, 47(2), pp. 180-196. doi: https://doi.org/10.5700/rausp1033

Medeiros, A. W. \& Mol, A. L. R. (2017). Tangibilidade e Intangibilidade na Identificação do Desempenho Persistente: Evidências no Mercado Brasileiro. Revista de Administração Contemporânea, 21(2), pp. 184-202. doi: https://dx.doi.org/10.1590/1982-7849rac2017150259

Mendes-da-Silva, W. (2011). Small Worlds and Board Interlocking in Brazil: A Longitudinal Study of Corporate Networks, 1997-2007. Revista Brasileira de Finanças, 9(4), pp. 521-548.

Mendes-da-Silva, W., Rossoni, L., Martin, D. L. \& Martelanc, R. (2008). A influência das redes de relações corporativas no desempenho das empresas do novo mercado da Bovespa. Revista Brasileira de Finanças, 6(3), pp. 337-358. 
Obstfeld, D. (2005). Social networks, the tertius iungens orientation, and involvement in innovation. Administrative Science Quarterly, 50(1), pp. 100-130. doi: https://doi.org/10.2189/asqu.2005.50.1.100

Pfeffer, J. \& Salancik, G. R. (1978). The external control of organizations: a resource dependence perspective. New York: Harper \& Row.

Provan, K. G., Fish, A. \& Sydow, J. (2007). Interorganizational networks at the network level: a review of the empirical literature on whole networks. Journal of Management, 33(3), pp. 479-516. 479-516. doi: https://doi.org/10.1177/0149206307302554

Ribeiro, F. \& Colauto, R. D. (2016). A relação entre board interlocking e as práticas de suavização de resultados. Revista Contabilidade \& Finanças, 27(70), pp. 55-66. doi: https://doi.org/10.1590/1808$057 \times 201501320$

Ribeiro, F., Colauto, R. D. \& Clemente, A. (2016). Determinantes da formação de board interlocking no mercado de capitais brasileiro. Revista de Educação e Pesquisa em Contabilidade, 10(4), pp. 398-415. doi: https://doi.org/10.17524/repec.v10i4.1403

Santos, R. L. \& Silveira, A. D. M. da. (2007). Board interlocking no Brasil: a participação de conselheiros em múltiplas companhias e seu efeito sobre o valor das empresas. Revista Brasileira de Finanças, 5(2), pp. 125-163.

Silveira, A. D. M. D., Barros, L. A. B. D. C. \& Famá, R. (2003). Estrutura de governança e valor das companhias abertas brasileiras. Revista de Administração de Empresas, 43(3), pp. 50-64. doi: http:// dx.doi.org/10.1590/S0034-7590200300030000

Vedel, M. (2016). The triad value function - theorizing the value potential of connected relationships. Journal of Business \& Industrial Marketing, 31(7), pp. 1-31. doi: https://doi.org/10.1108/JBIM-052015-0086

Wasserman, S. \& Faust, K. (1994). Social network analysis: methods and applications (8a ed.). Cambridge, MA: Cambridge University Press.

Watts, D. J. \& Strogatz, S. H. (1998). Collective dynamics of "small-world" networks. Letters to Nature, 393(6684), pp. 440-442. doi: https://doi.org/10.1038/30918

Zald, M. (1969). The power and functions of boards of directors: a theoretical synthesis. American Journal of Sociology, 75(1), pp. 97-111. 